\title{
Pemanfaatan Limbah Bongkol Jagung Untuk Pembuatan Briket Arang Sebagai Potensi Energi Alternatif
}

\author{
Abubakar Sidik Katili', Yuliana Retnowati'2, Ilyas H. Husain ${ }^{3}$ \\ ${ }^{1,2,3}$ Fakultas MIPA, Universitas Negeri Gorontalo, Jalan Prof. Dr. Ing. B.J.Habibie, \\ Tilongkabila, Kabupaten Bone Bolang, Indonesia \\ Email: abubakarsidik@ung.ac.id ${ }^{1^{*}}$,yuliana.retnowati@ung.ac.id ${ }^{2}$, \\ ilyas_husain@ung.ac.id ${ }^{3}$,
}

\begin{abstract}
Abstrak
Tujuan pengabdian ini adalah memberikan pengetahuan dan keterampilan pada masyarakat SP3 Saritani dalam memanfaatkan limbah pertanian bongkol jagung untuk menjadi bahan dasar briket arang sebagai energi alternatif. Target luaran dari program ini antara lain adanya kesempatan bagi mahasiswa untuk belajar bersama masyarakat tentang pembangunan desa (learning society). Metode pelaksanaan dalam kegiatan ini yakni Focus group discusion (FGD) antara mahasiswa dan pihak kelompok mitra. Melakukan obervasi langsung bersama dengan mitra dan mendokumentasikan potensi yang akan dikembangkan bersama masyarakat dampingan. Membuat rancangan skenario pelaksanaan program, melakukan pelatihan dan pendampingan untuk pengolahan limbah pertanian bongkol jagung untuk bahan baku produksi briket arang sebagai potensi energi alternatif. Hasil yang diperoleh yakni adanya produk arang briket berbahan dasar limbah bongkol jagung. Arang briket yang dihasilkan memiliki ciri fisik yang cukup ideal untuk pengunaanya sebagai bahan bakar alternatif. Bentuk fisik arang briket dalam bentuk silinder dengan tinggi sekitar $3 \mathrm{~cm}$ dan diameter sekitar $5 \mathrm{~cm}$ dan cukup keras dengan jenis perekat tepung kanji dengan persentase masing-masing 5\%, 10\% dan 15\%. Hasil uji yang telah dilakukan menyimpulkan bahwa proses uji penyalaan briket menjadi bara api yang siap untuk digunakan hanya membutuhkan waktu satu menit. Dampak yang diperoleh adalah adanya nilai produk yang dihasilkan untuk memberikan kemandirian secara ekonomi pada masyarakat SP3 Saritani. Kegiatan pengabdian ini juga telah menunjang penerapan inovasi dan teknologi yang berguna secara langsung dalam pencapaian SDGs pada goals ke 7 (desa berenergi bersih dan terbarukan) serta goals yang ke 15 (desa peduli lingkungan darat).
\end{abstract}

Kata Kunci: Arang briket, eneri alternative, bongkol jagung

\begin{abstract}
The purpose of this program to provide knowledge and skills to the SP3 Saritani community in utilizing agricultural waste of corn cob as the basic ingredients of charcoal briquettes as an alternative energy. External targets of this program include opportunities for students to learn with the community about village development (learning society). To implementation in this activity used Focus group discussion (FGD) between students and partner groups. Direct observation and excavations together with partners and document the potential resources that will be developed
\end{abstract}


with the assisted community. Designing scenarios for the implementation of the program, conducting training and mentoring for the processing of agricultural waste of corn cobs for raw materials of charcoal briquette production as an alternative energy potential. The result obtained is the existence of charcoal briquette products made from corn waste. Charcoal briquettes produced have physical characteristics that are ideal enough as an alternative fuel. The physical shape of charcoal briquettes in the form of cylinders with a height of about $3 \mathrm{~cm}$ and a diameter of about $5 \mathrm{~cm}$ and hard enough with a type of starch adhesive with a percentage of $5 \%, 10 \%$ and $15 \%$ respectively. The test results concluded that the process of ignition of briquettes into coals that are ready for use takes only one minute. The impact obtained is the value of products produced to provide economic independence to the SP3 Saritani community. This devotional activity has also supported the application of innovations and technologies that are directly useful in achieving SDGs on the 7th goals (clean and renewable energy villages) and the 15th goals (villages care about the land environment).

Keywords: Charcoal briquettes, alternative energy, corncobs

(C) 2021 Abubakar Sidik Katili, Yuliana Retnowati, Ilyas H. Husain Under the license CC BY-SA 4.0 Correspondence author: llyas H Husain, ilyas_husain@ung.ac.id, Gorontalo, and Indonesia

\section{PENDAHULUAN}

Kebutuhan akan energi semakin meningkat seiring dengan meningkatnya aktivitas manusia yang menggunakan bahan bakar terutama bahan bakar minyak yang diperoleh dari fosil tumbuhan maupun hewan. Ketersediaan bahan bakar fosil yang semakin langka berakibat pada kenaikan harga BBM. Di Indonesia kebutuhan dan konsumsi energi terfokus pada penggunaan bahan bakar minyak yang cadangannya makin menipis (Smith, 2017). Negara kita ini dikarunia berbagai sumberdaya energy fosil dengan jumlah yang relative terbatas sehingga dengan pemakaian seperti saat ini cadangan tersebut akan habis dalam waktu yang tidak terlalu lama. padahal kita memiliki bermacam-macam sumberdaya energi alternatif yang saat ini belum dikembangkan secara optimal (Boedoyo, 2007).

Ketersediaan sumber energi utama yang terbatas, menyebabkan perlu adanya pengembangan sumber energy alternatif sebagai upaya 
pemenuhan konsumsi energy yang sangat tinggi dan mengurangi penggunaan bahan bakar fosil dalam kegiatan industri dan rumah tangga. Sumber energi alternatif yang dapat diperbaharui di Indonesia cukup banyak, diantaranya adalah biomassa atau bahan-bahan limbah organik (Putro, 2014).

Briket (bioarang) merupakan energi biomassa yang ramah lingkungan dan biodegradable. Briket mempunyai keuntungan ekonomis yang tinggi yaitu mudah dibuat dan memiliki nilai kalor yang tinggi (Heruwati, 2009). Bahan dasar briket adalah merupakan padatan berpori hasil proses pembakaran bahan yang mengandung karbon dengan kondisi tanpa oksigen sehingga bahan hanya terkarbonisasi dan tidak teroksidasi. Sebagian besar pori pada arang masih tertutup oleh hidrogen, tar, dan senyawa organik lain yang komponennya terdiri dari abu, air, nitrogen, dan sulfur. Pada prinsipnya pembriketan adalah proses pengempaan bahan berukuran partikel kecil yang berasal dari limbah organik, limbah pabrik, maupun limbah perkotaan di dalam suatu cetakan untuk diperoleh struktur padatan yang rapat dan kompak. Biasanya briket terbuat dari kayu yang dibakar kemudian dicetak. Namun, penggunaan kayu sebagai bahan baku pembuatan briket akan menjadi tidak efektif dan efisien karena menyebabkan banyaknya pohon yang harus ditebang. Maka dari itu, limbah limbah organic pertanian berupa bongkol jagung dapat dipilih menjadi alternatif bahan baku yang efektif dan efisien dalam pembuatan briket. Dalam pembuatan briket ini, teknologi yang dapat dimanfaatkan untuk mengolah limbah bongkol jagung ini adalah proses karbonisasi. Terdapat bahan tambahan lain yang berfungsi sebagai perekat (binder) yaitu plastik tepung kanji, menurut Nurkiani (2020) besaran nilai kalor 
tepung kanji sebagai bahan perekat Briket arang dikisaran nilai 5181 $\mathrm{Kal} / \mathrm{g}$, fakta ini membuktikan tepung kanji sesaui dengan syarat SNI memenuhi syarat briket yang baik yaitu dengan kisaran nilai $5000 \mathrm{Kal} / \mathrm{g}$.

Salah satu hasil komoditi perkebunan di kecamatan Wonosari adalah Jagung, khususnya di desa Sari Tani hasil perkebunan jagung sebagian besar dijual dan sebagian kecil dimanfaat untuk kebutuhan rumah tangga antara lain bahan makanan. Banyaknya hasil pengolahan jagung ini menghasilkan bongkol jagung yang tidak termanfaatkan secara maksimal sehingga bisa menjadi limbah organic hasil perkebunan yang ada di Desa Saritani.

Ketersediaan bongkol jagung yang cukup melimpah akan tetapi belum termanfaatkan secara maksimal perlu dicari alternatif pengolahannya sehingga dapat menjadi sumber energy variatif baru dan terbarukan dan lebih diminati oleh masyarakat untuk dimanfaatkan. Hal ini perlu dilakukan mengingat kebutuhan akan energy kian meningkat dan sumber energi kian terbatas. Selain itu untuk menunjang peningkatan ekonomi masyarakat pedesaan dengan memafaatkan produk yang rama lingkungan sehingga diharapkan melalui program ini akan terwujudnya Perdesaan yang memiliki keunggulan Kolaboratif dan Daya Saing secara berkelanjutan dalam mendukung Indonesia maju yang berdaulat, Mandiri, dan berkepribadian, berlandaskan GotongRoyong dalam hal pemanfaatan energi.

\section{METODE PELAKSANAAN}

Metode yang digunakan adalah kerjasama antara mahasiswa dengan kelompok mitra mengimplementasikan program yang telah direncanakan dan disepakati. Metode yang akan d implementasikan 
tersebut antara lain; obervasi langsung bersama dengan mitra dan mendokumentasikan potensi yang akan dikembangkan bersama masyarakat dampingan, Focus Group Discussion antara mahasiswa dan kelompok mitra, membuat rancangan skenario pelaksanaan program, melakukan pelatihan untuk pengolahan limbah pertanian bongkol jagung untuk bahan baku produksi briket arang, penguatan kelembagaan dengan menggunakan metode kerjasama antara mahasiswa dan masyarakat dalam hal ini kelompok mitra mengimplementasikan program dalam bentuk rumah produksi sederhana, pendampingan kepada mahasiswa dan kelompok mitra dalam dalam implementasi program.

\section{HASIL DAN PEMBAHASAN}

\section{Hasil}

a. Deskripsi Lokasi KKN Tematik Desa Membangun SP-3 Desa Sari Tani Kecamatan Wonosari Kabupaten Boalemo

Desa Saritani dahulu hanya memiliki 4 Dusun, yang di antaranya yaitu Dusun Huto, Tangga, Nooti, dan Longgi, keempat Dusun ini memiliki Asal Usul Nama yang Unik, seperti huto dan Nooti, Nama tersebut di ambil dari Nama Kepala suku Asli Dulu, Suku Asli yang pertama kali tinggal di Desa tersebut adalah suku Polahi, kemudian dengan berjalannya waktu terjadilah pemekaran dusun hingga sekarang, Desa Saritani memiliki 25 dusun dan sekarang desa saritani memiliki jumlah penduduk 4.925 Jiwa, yang berasal dari berbagai suku. Penduduk Desa Saritani Sebagaian besar berkerja sebagai Petani, sumber penghasilan utama masyarakat desa saritani berasal dari sektor pertanian berupa tanaman pangan seperti halnya padi, Palawija 
( jagung, kacang-kacangan, ubi dll) dan tanaman perkebunan berupa kelapa sawit.

Unit Permukiman Transmigrasi Pangea SP-3 pada dasarnya dikonsepkan sebagai calon pusat pertumbuhan baru, yang dalam hal ini pemerintah berkewajiban membina dan mendorong masyarakat di Lokasi Transmigrasi agar mampu berusaha mandiri sesuai dengan potensi dan daya dukung lingkungan Bio-Geofisik serta sosial budaya dipermukiman, hingga pada gilirannya mereka dapat segera mewujudkan harapan hidup sejahtera dan mandiri.

Profil UPT Pangea SP-3 Kecamatan Wonosari Kabupaten Boalemo Propinsi Gorontalo ini antara lain memuat potensi Sumber Daya Alam (SDA), Sumber Daya Manusia (SDM), Perkembangan Perekonomian dan permasalahan yang terdapat dilokasi serta upaya-upaya yang perlu dilakukan oleh pemerintah Daerah maupun pusat. Sehingga dapat diharapkan atau dijadikan sebagai bahan instrumen dalam penentuan kebijakan pemerintah tentang pemberdayaan masyarakat di UPT Pangea SP-3 Kecamatan Wonosari Kabupaten Boalemo Propinsi Gorontalo serta untuk referensi penelitian atau analisa lebih lanjut.

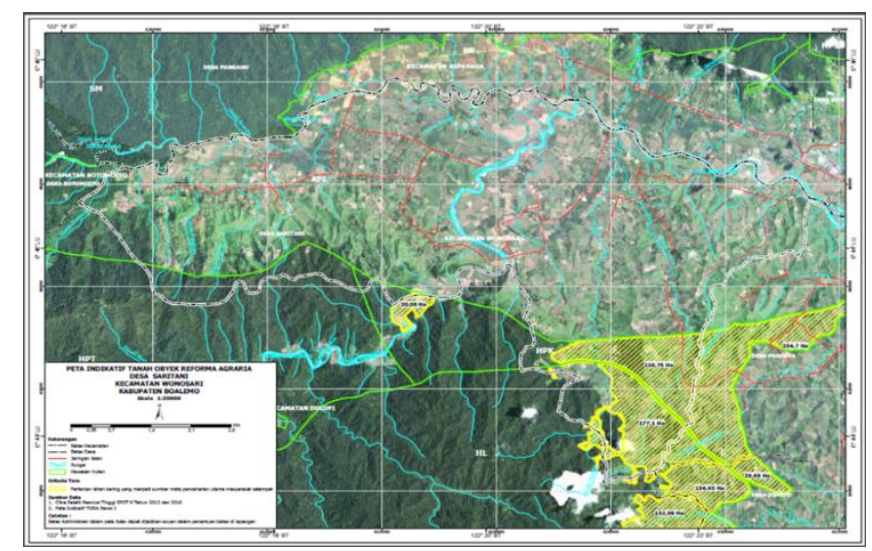

Gambar 1. Peta Wilayah SP-3 Saritani 


\section{Pembahasan}

KKN Tematik Desa Membangun di UPT SP-3 Pangea Desa Sari Tani Kecamatan Wonosari Kabupaten Boalemo tahun 2021 memiliki program utama "Pemanfaatan Limbah Perkebunan Tongkol Jagung Untuk Pembuatan Briket Arang Sebagai Potensi Energi Alternatif di Desa Sari Tani”. Briket dari Limbah Tongkol Jagung tersebut dapat bemanfaat untuk mengurangi beban pengeluaran masyarakat khususnya terkait belanja pemenuhan kebutuhan untuk memasak. Biomassa yang berasal dari limbah hasil pertanian merupakan bahan yang tidak berguna, tetapi dapat dimanfaatkan menjadi sumber energi bahan bakar alternatif, yaitu dengan mengubahnya menjadi bioarang yang memiliki nilai kalor lebih tinggi daripada biomassa melalui proses pirolisis. Menipisnya cadangan bahan bakar fosil akan berdampak pada perekonomian. Bahan bakar fosil sudah menjadi bahan bakar yang biasa digunakan untuk memenuhi kebutuhan energi dewasa ini, sedangkan para penggunanya terkadang tidak memikirkan bahwa sumber energi tersebut tidak dapat diperbaharui masyarakat. Desa apabila briket arang berbahan dasar limbah tongkol jagung berbasis masyarakat kemudian dilanjutkan serta direalisasikan baik oleh Pemerintah Desa Sari Tani maupun masyarakat setempat dimasa yang akan datang. Berikut adalah karakteristik Briket Arang yang dihasilkan selama Kegiatan mahasaiswa KKN : Briket arang yang dihasilkan mempunyai bentuk silinder dengan tinggi sekitar $3 \mathrm{~cm}$ dan diameter sekitar $5 \mathrm{~cm}$ dan cukup keras dengan jenis perekat tepung Kanji dengan persentase masing-masing 5\%, 10\% dan 15\%. Secara fisik briket yang dihasilkan cukup baik. Uji pendahuluan dilakukan dengan uji penyalaan awal, briket yang telah dibuat membutuhkan waktu sekitar 1 
menit untuk menjadi bara api, Berikut Pembuatan Briket Berbahan Dasar Limbah Tongkol Jagung yang telah dilakukan Selama Kegiatan Oleh mahasiswa KKN Tematik Desa membangun.

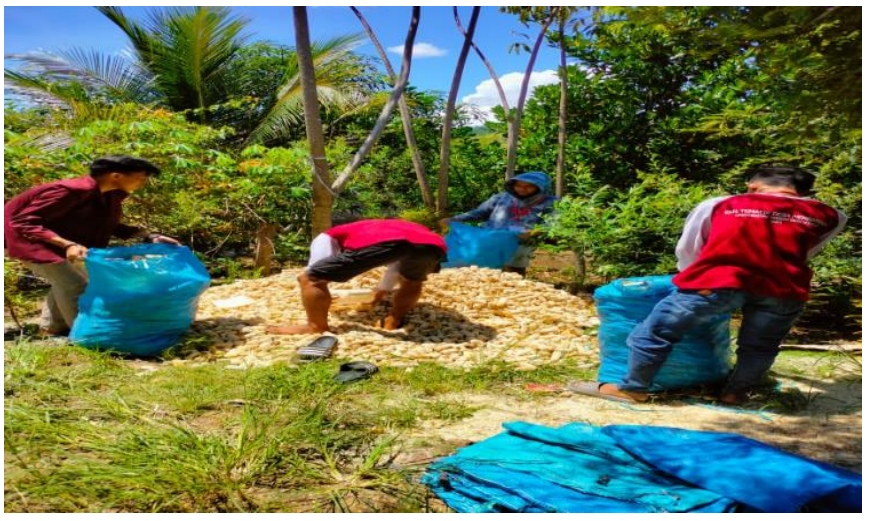

Gambar 2. Pengumpulan Limbah Tongkol Jagung

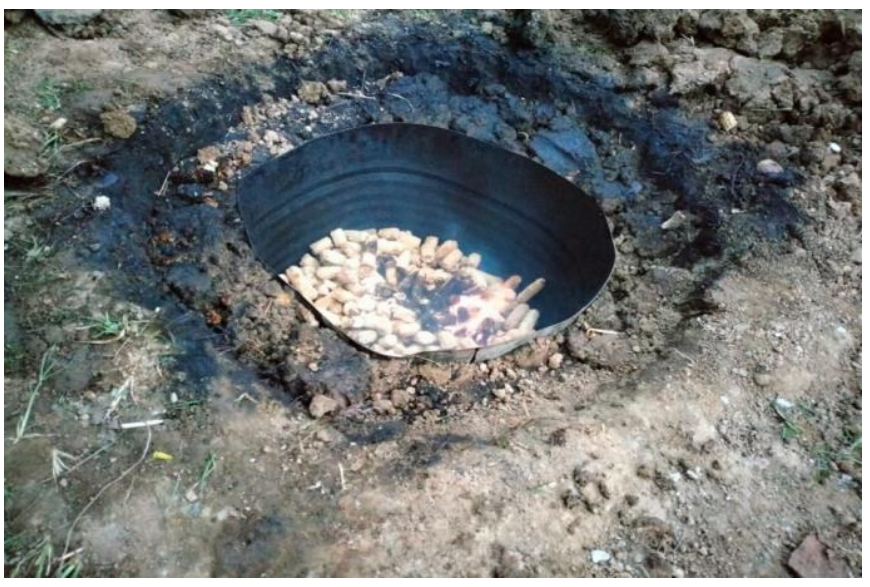

Gambar 3. Proses Pembakaran Tongkol Jagung 


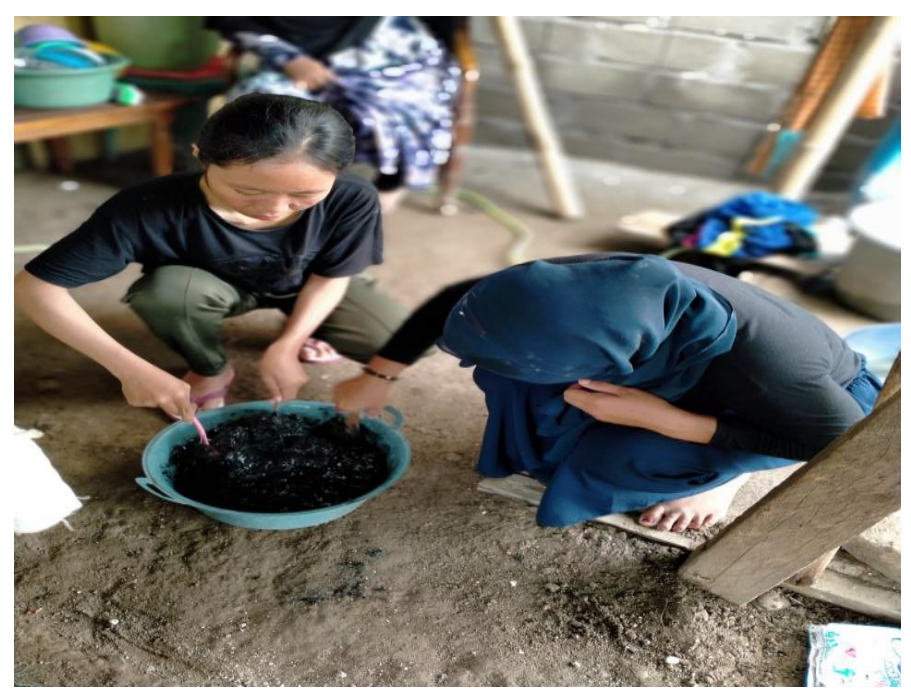

Gambar 4. Pencampuran arang dengan Perekat

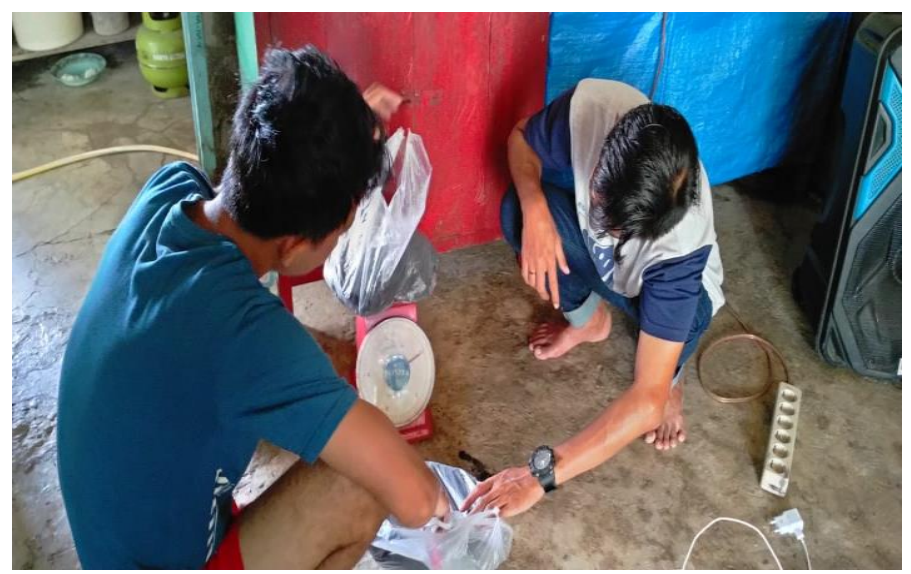

Gambar 5. Pengukuran bahan perekat 


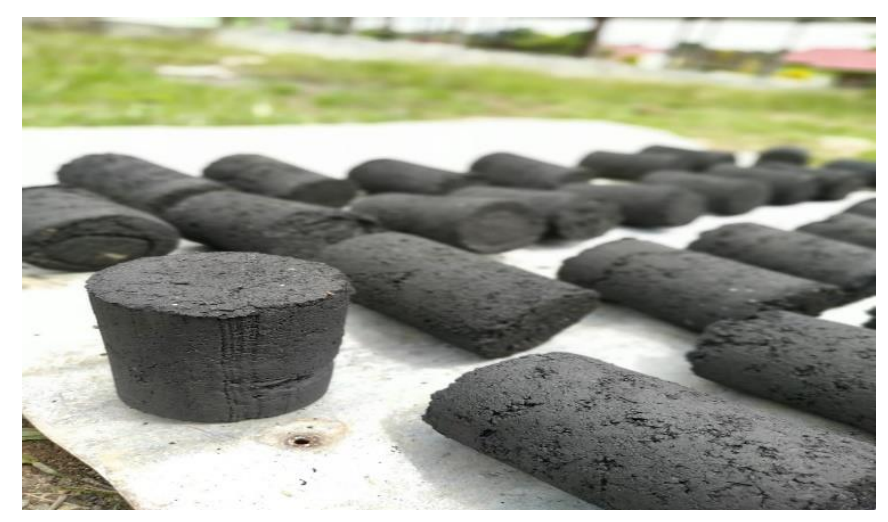

Gambar 5. Hasil Briket yang telah di Cetak

Berdasarkan beberapa gambar di atas kita dapat melihat hasil Tampilan Briket berbahan dasar Limbah Tongkol Jagung yang telah rancang oleh mahasiswa. Gambaran ini didasarkan oleh hasil obsevasi lokasi yang telah dilakukan sebelumnya dan beberapa arahan dari Pemerintah Desa Sari Tani dan DPL serta sebagian masyarakat UPT SP-3 Pangea.

Briket yang baik harus memenuhi standar yang telah ditentukan agar dapat dipakai sesuai dengan keperluannya. Untuk mengetahui kualitas briket yang dihasilkan maka perlu dilakukan uji yang dibatasi meliputi kadar air, kadar zat menguap, kadar abu, kadar karbon terikat serta nilai kalor Kadar air akan mempengaruhi mudah tidaknya briket tersebut untuk dibakar. Semakin tinggi kadar air maka briket akan semakin sulit dibakar, sehingga kalor yang dihasilkan juga akan semakin rendah. kadar air briket arang tongkol jagung sekitar 3,66\% sampai $6,01 \%$. Perlu adanya analisis kadar air agar dapat diperoleh kadar air semua briket arang tongkol jagung sudah memenuhi standar SNI 01-6235-2000 yaitu di bawah 8\%, jenis perekat dan persentase 
perekat memberi pengaruh yang berarti terhadap kadar air yang terkandung dalam briket. Hal ini sesuai dengan hasil penelitian terdahulu yang dilakukan oleh Maryono, Sudding dan Rahmawati (2013), bahwa pada penambahan perekat yang semakin tinggi menyebabkan air yang terkandung dalam perekat akan masuk dan terikat dalam pori arang, selain itu penambahan perekat yang semakin tinggi akan menyebabkan briket mempunyai kerapatan yang semakin tinggi pula sehingga pori-pori briket akan semakin kecil dan pada saat dikeringkan air yang terperangkap di dalam pori briket sukar menguap. Selain jenis perekat dan persentase perekat, faktor lain yang mempengaruhi kadar air dalam briket adalah waktu pengeringan bahan baku briket serta waktu pengeringan briket.

Selain itu Kandungan kadar zat menguap yang tinggi di dalam briket arang akan menimbulkan asap yang lebih banyak pada saat briket dinyalakan, sebab adanya reaksi antara karbon monoksida, Menurut standar SNI 01-6235-2000 parameter briket yang baik yaitu bahan yang hilang pada pemanasan $950^{\circ} \mathrm{C}$ maksimal $15 \%$, dari data uji yang telah dilakukan hanya briket arang dengan perekat tepung tapioka $5 \%$ dan briket arang dengan perekat $5 \%$ yang memenuhi standar, jenis perekat dan persentase perekat mempengaruhi kadar zat menguap dalam briket, karena perekat yang ditambahkan pada proses pencetakan briket tidak mengalami proses pirolisis (proses pengarangan), kandungan zat-zat menguap seperti $\mathrm{CO}, \mathrm{CO} 2, \mathrm{H} 2, \mathrm{CH} 4$ dan $\mathrm{H} 2 \mathrm{O}$ yang dihasilkan oleh perekat pada saat uji kadar zat menguap akan memperbesar kadar zat menguap, sesuai dengan penelitian terdahulu yang dilakukan oleh Maryono, Sudding dan Rahmawati [1] yang menyatakan bahwa pada waktu pemanasan briket arang, perekat yang 
digunakan ikut menguap sehingga kadar zat yang hilang pada pemanasan $950^{\circ} \mathrm{C}$ yang dihasilkan menjadi lebih besar dengan bertambahnya perekat.

Kadar abu adalah persentase dari zat-zat yang tersisa dari proses pembakaran dan sudah tidak memiliki unsur karbon. Semakin tinggi kadar abu dalam suatu briket maka kualitas briket akan semakin rendah, karena kandungan abu yang tinggi dapat menurunkan nilai. Menurut standar SNI 01-6235-2000 briket dengan kualitas baik harus memiliki kadar abu maksimal $8 \%$, sehingga jika dibandingkan dengan standar SNI tersebut semua briket yang telah dibuat sudah memenuhi standar kecuali briket arang dengan perekat tepung terigu persentase $15 \%$, jenis perekat dan persentase perekat berpengaruh secara signifikan terhadap kadar abu briket. perekat inilah yang menyebabkan perbedaan kandungan abu masing- masing briket, selain itu semakin banyak penambahan abu yang berasal dari kandungan bahan anorganik dalam perekat maka kadar abu yang dihasilkan akan semakin tinggi pula.

\section{KESIMPULAN}

Pengelolaan dan pemanfaatan bahan local menjadi salah satu sumber energy alternatif perlu didukung oleh pengetahuan ilmiah yang relevan sehingga meningkatkan serta memperkuat kesadaran akan pentingnya eksistensi dan nilai jasa lingkungan. Bentuk kegiatan yang mendukung ide tersebut yakni melalui transfer pengetahuan ilmiah dan implementasinya. Bentuk transfer pengetahuan ilmiah tersebut berupa penyusunan strategi pemanfaatan dan pengelolaan bahan local menjadi sumber energy alternatif. Dengan adanya hal tersebut diharapkan dapat menjadi dasar dalam keberlanjutan pengelolaan dan 
pemanfaatan bahan local yang tetap mempertimbangkan aspek ramah lingkungan.

\section{UCAPAN TERIMA KASIH}

Ucapan terima kasih kepada seluruh masyarakat dan Pemerintah Desa Saritani khususnya UPT SP-3 Pangea, Pemerintah Kecamatan Wonosari dan Pemerintah Kabupaten Boalemo yang telah mendukung terlaksananya kegiatan KKN Tematik Desa Membangun di Sari Tani Dusun SP-3 Pangea dan kepada Lembaga Penelitian dan Pengabdian pada Masyarakat (LPPM), Universitas Negeri Gorontalo atas dukungan Dana KKN Tematik Desa Membangun PNBP 2021.

\section{REFERENCES}

Boedoyo, S,M 2007, Pengembangan Teknologi Energi Alternatif untuk Mendukung Ketahanan dan Kemandirian Energi Nasional, BPPT-Press, Jakarta,

Heruwati, L.D. (2009). Pengaruh Variasi Tekanan pada Pembuatan Briket Arang Tempurung Kelapa dengan Perekat Daun Jambu Mete Muda (Anacardium occidentale L.) terhadap Nilai Kalor yang Dihasilkan. Surakarta: Universitas Muhammadiyah.

Nurkiani Jail Ali, Muhammad Anas, Erniwati. (2020) Pengaruh Variasi Bahan Perekat terhadap Nilai Kalor dan Waktu Nyala Briket Arang Ban Bekas. Online at http://ojs.uho.ac.id/index.php/JIPFI p-ISSN: 2502-3861

Putro, S., Musabbikhah, dan Sri Hartati. 2014. Setting Parameter yang Optimal pada Proses Pembriketan Limbah Biomassa Guna mendapatkan Kadar Air Briket Minimal dalam menciptakan Energi Alternatif yang Ekonomis. Universitas Muhammadiyah. Surakarta.

Standar Nasional Indonesia. 2000. SNI Briket Arang Kayu SNI 016235-2000. Badan Standarisasi Nasional- BSN. 
Smith, H \& Syarifuddin Idrus 2017, „Pengaruh Penggunaan Perekat Sagu dan Tapioka terhadap Karakteristik Briket dari Biomassa Limbah Penyulingan Minyak Kayu Putih di Maluku", Ejournal kemenperin, hh. 21-32.

DOI:http://dx.doi.org/10.29360/mb.v13i2.3546.

Yandi bagus., 2007. Bahan Energi Alternatif. Jawa Pos, 22 Juni 2007).

Yandi bagus, 2007. Bahan Energi Alternatif. Jawa Pos. Rabu, 30 Mei 2007

Zapusek, A., Wirtgen, C., Lenart, F., 2003, Characterisation Of Carbonizate Produced From Velenje Lignite In Lab-Scale Reactor, ERICo Velenje, Institute for Ecological reseach, Koroska 58, 3320 Velenje, Slovania. 